\title{
Reproductive ecology of the endangered Beal's-eyed turtle, Sacalia bealei
}

Liu Lin ${ }^{1}$, Qingru Hu ${ }^{1}$, Jonathan Julio Fong ${ }^{2}$, Jiangbo Yang ${ }^{1}$, Zhongdong Chen ${ }^{3}$, Feiyu Zhou ${ }^{3}$, Jichao Wang ${ }^{1}$, Fanrong Xiao ${ }^{1}$, Haitao Shi ${ }^{\text {Corresp. } 1}$

${ }^{1}$ Ministry of Education Key Laboratory for Ecology of Tropical Islands, College of Life Sciences, Hainan Normal University, Haikou, Hainan, China

2 Science Unit, Lingnan University, Hongkong, Hongkong, China

3 Administration Bureau, Fujian Huboliao National Nature Reserve, Zhangzhou, Fujian, China

Corresponding Author: Haitao Shi

Email address: haitao-shi@263.net

The Beal's-eyed turtle (Sacalia bealei) is endemic to southeastern China and endangered due to poaching and habitat loss. Knowledge of $S$. bealei ecology is lacking and this study provides baseline information of its reproduction in a natural environment. We studied the reproductive ecology of $S$. bealei using X-ray, spool-and-line tracking, and direct observation. Six nesting females were successfully tracked and their nesting behaviors are documented in detail. Females produced a mean clutch size of 2.2 eggs (range 1-3). The hard-shelled eggs were ellipsoidal with a mean length of $45.50 \mathrm{~mm}$, a mean width of 23.20 $\mathrm{mm}$, and mean weight of $14.8 \mathrm{~g}$. The relative clutch mass (RCM) was $9.47 \%$, while the relative egg mass (REM) was $4.60 \%$. The mean incubation period was 94.7 days with a mean nest temperature of $25.08^{\circ} \mathrm{C}$. Hatchlings had a mean weight of $9.7 \mathrm{~g}$, carapace length of $40.1 \mathrm{~mm}$, carapace width of $33.3 \mathrm{~mm}$, carapace height of $17.4 \mathrm{~mm}$, plastron length of $31.6 \mathrm{~mm}$, and plastron width of $25.4 \mathrm{~mm}$. The results of this study provide important information to inform conservation plan and ex-situ breeding for this endangered species. 
1

2

3

4

$5{ }^{1}$ Ministry of Education Key Laboratory for Ecology of Tropical Islands, College of Life Sciences, Hainan

6 Normal University, Haikou 571158, China

$7 \quad{ }^{2}$ Science Unit, Lingnan University, Hong Kong, China

$8{ }^{3}$ Administration Bureau of Fujian Huboliao National Nature Reserve, Zhangzhou 363600, China

9 Corresponding Author: Haitao Shi, haitao-shi@263.net

10

Reproductive ecology of the endangered Beal's-eyed turtle, Sacalia bealei

Liu Lin ${ }^{1}$, Qingru Hu${ }^{1}$, Jonathan Julio Fong ${ }^{2}$, Jiangbo Yang ${ }^{1}$, Zhongdong Chen ${ }^{3}$, Feiyu Zhou ${ }^{3}$, Jichao $\mathrm{Wang}^{1}$, Fanrong Xiao ${ }^{1}, \quad$ Haitao Shi ${ }^{*}$

1 ABSTRACT

The Beal's-eyed turtle (Sacalia bealei) is endemic to southeastern China and endangered due to poaching and habitat loss. Knowledge of $S$. bealei ecology is lacking and this study provides baseline information of its reproduction in a natural environment. We studied the reproductive ecology of $S$. bealei using X-ray, spool-and-line tracking, and direct observation. Six nesting females were successfully tracked and their nesting behaviors were documented in detail. Females produced a mean clutch size of 2.2 eggs (range 1-3). The hard-shelled eggs were ellipsoidal with a mean length of $45.50 \mathrm{~mm}$, a mean width of $23.20 \mathrm{~mm}$, and mean weight of $14.8 \mathrm{~g}$. The relative clutch mass (RCM) was $9.47 \%$, while the relative egg mass (REM) was $4.60 \%$. The mean incubation period was 94.7 days with a mean nest temperature of $25.08^{\circ} \mathrm{C}$. Hatchlings had a mean weight of $9.7 \mathrm{~g}$, carapace length of $40.1 \mathrm{~mm}$, carapace width of $33.3 \mathrm{~mm}$, carapace height of $17.4 \mathrm{~mm}$, plastron length of $31.6 \mathrm{~mm}$, and plastron width of $25.4 \mathrm{~mm}$. The results of this study provide important information to inform conservation plans and ex-situ breeding for this endangered species.

\section{INTRODUCTION}

The reproductive biology of a species is an important component of its overall life history strategy (Gibbons, 1982). Thus, understanding reproductive ecology is important for turtle 
management and conservation (Tucker \& Moll, 1997; Horne et al., 2003). Studies of turtle reproductive ecology have revealed important direct and indirect effects on fitness and demography (Bobyn \& Brooks, 1994; Weisrock \& Janzen, 1999; Valenzuela, 2001; Spencer and Thompson, 2003; Janzen et al., 2007).

The Beal's-eyed Turtle (Sacalia bealei), endemic to southeastern China, is distributed in Guangxi, Guangdong, Fujian, Anhui, Guizhou, Jiangxi Provinces, and Hong Kong (Shi et al., 2008). It is listed as endangered on the IUCN Red List (van Dijk et al., 2012) and Appendix II of CITES. Poaching pressure on S. bealei is strong, with the pet trade price increasing from 1500 $\mathrm{RMB} / \mathrm{kg}$ in 2014 to $4200 \mathrm{RMB} / \mathrm{kg}$ in 2015 (Hu et al., 2016). Due to illegal poaching and trade, $S$. bealei has become extremely rare in the field (Shi et al., 2005; Gong et al., 2017a). Life history of this species is poorly understood, with only a few observations on diet and reproduction in captivity (Zhang et al., 1998; Gong et al., 2017b). This study provides baseline information on the reproductive biology of $S$. bealei in a natural environment.

\section{METHODS}

\section{Study site}

We conducted field research in Huboliao National Nature Reserve, Fujian Province, China $\left(117^{\circ} 12^{\prime} 42^{\prime \prime} \sim 117^{\circ} 22^{\prime} 45^{\prime \prime} \mathrm{E} ; 24^{\circ} 30^{\prime} 05^{\prime \prime} \sim 24^{\circ} 56^{\prime} 20^{\prime \prime} \mathrm{N}\right)$. The mean annual temperature in Huboliao is $21.1{ }^{\circ} \mathrm{C}$, with the lowest temperature in January (mean $10.9^{\circ} \mathrm{C}$ ) and the highest in July (mean $26.7^{\circ} \mathrm{C}$ ). The mean rainfall is $1733.5 \mathrm{~mm}$, with a mean relative humidity of $81.4 \%$. The major vegetation types in this reserve are evergreen broad-leaved forest, mixed forest, and bamboo forest (Fan, 2001) (Fig. 1).

\section{Methods}

In late March 2015, when turtles had completed their hibernation (from early November to mid March), we used traps to capture them. When females were captured, we brought them back to the field station for further inspection. We used portable X-ray radiography (BJI $-\mathrm{UJ}$ ) to confirm the presence and number of oviductal eggs. If shell-eggs were found, a plastic spooland-line tracker was attached to the carapace of the female (Fig. 2). The spool-and-line tracker was composed of two parts: 1) a white box (diameter $35 \mathrm{~mm}$, height $23 \mathrm{~mm}$ ) with an internal line spool (diameter $30 \mathrm{~mm}$, height $19 \mathrm{~mm}$ ), fastened to the carapace using epoxy resin, 2) a black 
60 external line spool (diameter $35 \mathrm{~mm}$, height $23 \mathrm{~mm}$ ), which was attached to the line and used afterwards for retrieval. The tracker weighed $8 \mathrm{~g}$ and contained $70 \mathrm{~m}$ fishing line. We designed the tracker and have successfully used it to track daily movement of the red-eared slider (Trachemys scripta elegans) during the nesting period ( $L i$, 2013; Yang, 2014). In total, 10 females with evidence of shell-eggs were tracked. We took morphological measurements of these individuals (weight, carapace length, carapace width, body height, plastron length, and plastron width) following methods in Xiao et al. (2014).

From 8:00 am each day, we followed the fishing line of the 10 females to track their movement. The fishing line was retrieved carefully and spooled back into the white box every day to ensure the line was not used up and so the turtles could move freely. The presence of fishing line on land indicated that the individual was attempting to nest. When we encountered such a situation, we took notes on the nesting and egg-laying behavioral patterns, minimizing disturbance by observing using binoculars from 8-10 m away. After the turtle laid eggs and returned back to the stream, we checked the nest, recording (1) nest chamber characters (e.g. size and nest materials), (2) clutch size and egg measurements (length, width, and weight), (2) distance crawled by the female before nesting (following the fishing line), and (4) straight distance between the nest and the stream bank. Developing and undeveloping eggs were distinguished by the presence of a white spot on the eggshell. Relative egg mass (REM) (mean egg weight/body weight before oviposition) and relative clutch mass (RCM) (clutch weight/body weight before oviposition $=$ REM $\mathrm{x}$ clutch size) were calculated for each gravid female as estimates of reproductive effort (Wang et al., 2011). To monitor the temperature and humidity of the nest during incubation, we buried a data logger (HOBO U23-001, Onset Computer Inc., USA) at $10 \mathrm{~cm}$ distance to the nest and at the same depth. To prevent predation, we placed a wire net above the nest.

We checked the nests at least twice a week during incubation. When hatchling turtles emerged from the nests, we measured their weight, carapace length, carapace width, plastron length, and body height. Hatchlings were taken back to the field station and released back to the stream when the yolk sac was completely absorbed. Data loggers were retrieved after hatchling 
88

89

90

emergence, and the data were downloaded by HOBOware Graphing \& Analysis Software (Onset Computer Inc., USA).

The field study was approved by Administration and Services Centre of Nanjing County, Fujian Provinc (No. 20141203NJ0173). The animal ethics was approved by Animal Research Ethics Committee of Hainan Provincial Education Center for Ecology and Environment, Hainan Normal University (No. HNECEE-2014-003).

\section{Data analysis}

Statistical analyses were performed in SPSS 19.0. Descriptive statistics were expressed by mean \pm standard error. Significance level was set to 0.05 . We used linear regression to investigate the relationship between female body size and clutch or egg size.

\section{RESULTS}

\section{Timing and behavior sequence of nesting}

The ten gravid females captured in this study had a mean weight of $329.6 \pm 11.8 \mathrm{~g}$, carapace length of $136.3 \pm 1.5 \mathrm{~mm}$, carapace width of $94.4 \pm 1.1 \mathrm{~mm}$, carapace height of $51.3 \pm 0.8 \mathrm{~mm}$, plastron length of $121.7 \pm 1.5 \mathrm{~mm}$, and plastron width of $78.8 \pm 0.9 \mathrm{~mm}(\mathrm{n}=10)$. Among them, six individuals were successfully tracked. The remaining four individuals were lost because the fishing line broke. The nesting activities lasted from May 3-31. For the six females, we recorded 10 nesting activities - four failed attempts and six successful nesting. All observed nesting activities happened on rainy days and egg laying only happened at night. The behavior sequences of nesting could be categorized into five successive steps: 1) nest-site selection, 2) chamber excavation, 3) egg laying, 4) nest covering, and 5) returning to water.

During the nest-site selection, females emerged from water and made their way into the forest. Movement was not continuous, but instead occurred in stops and starts. During the pauses, individuals often elevated their head a few centimeters above the carapace and move side-to-side a few times, possibly as a vigilance behavior. While moving, the ground substrate did not impede 
115

116

117

118

119

120

121

122

123

124

125

126

127

128

129

130

131

132

\section{3}

134

135

136

137

138

139

140

141

their movement - they crawled along rocks, fallen wood, thick leaves, and gentle slopes. Often, females would attempt to dig nests 1-2 times before they chose the final site.

After finding the right site, females excavated the nest chamber, alternating between the two hindlimbs. After completing excavation, females used the rear portion of its carapace to hit the nest 4-6 times. The chamber excavation lasted 40-60 minutes.

After resting approximately 20 minutes, females would start laying eggs with hindlimbs straddling the chamber opening. To expel eggs, forelimbs and head would completely extend then simultaneously withdraw. Body tremors were obvious when the eggs were released into the nest. In total, egg laying lasted 8-15 minutes. No vigilance behaviors were observed during this sequence.

Nest covering began immediately after laying the last egg. Soil and leaves were packed down using alternate, backward movements of the hindlimbs, followed by a bobbing motion of the plastron that further compressed the soil and leaves into the nest chamber. Nest covering lasted 40-70 minutes.

After covering the nest, females immediately returned to water. While returning to the water, similar behaviors to those when choosing a nest-site were exhibited, such as movement in stops and starts, and crawling along rocks and fallen wood.

\section{Nest and egg characteristics}

Each of the six tracked females laid eggs in a nest. The number of eggs in each nest was consistent with the number of oviductal eggs seen in the x-ray, showing all eggs were laid at once. Straight distance from nest to the stream bank was $8.55 \pm 1.23 \mathrm{~m}(\mathrm{n}=6)$, while straight distance from nest to the sites where they emerged from and returned to water, was $11.47 \pm 1.31$ $\mathrm{m}$ and $16.55 \pm 2.93 \mathrm{~m}(\mathrm{n}=6)$, respectively. Females crawled a distance of $42.671 .47 \pm 7.18 \mathrm{~m}$ $(n=6)$ to choose a nesting site.

Nests were well camouflaged by leaves and soil (Fig. 3), making it difficult to find nests without the help of fishing line. The shape of nests was hemispherical, with a diameter of 70-100 
142 143

$\mathrm{mm}$ and depth of 55-70 $\mathrm{mm}$. Due to the relatively shallow depth, eggs were often half-buried by soil then covered by leaves.

The mean clutch size was $2.2 \pm 0.3$ (range $1-3, \mathrm{n}=6$ ). The hard-shell eggs were ellipsoidal, and weighed $14.8 \pm 0.8 \mathrm{~g}$, with a length of $45.5 \pm 1.0 \mathrm{~mm}$ and width of $23.2 \pm 0.5 \mathrm{~mm}(\mathrm{n}=13)$. A negative, linear correlation was found between mean egg length and female plastron width (Pearson correlation coefficient $=0.934, \mathrm{R}^{2}=0.934, \mathrm{P}<0.05$ ), and a positive, linear correlation found between mean egg width and female carapace height (Pearson correlation coefficient $=$ $\left.0.847, \mathrm{R}^{2}=0.718, \mathrm{P}<0.05\right)$. The mean RCM was $9.47 \pm 1.01 \%(5.14-12.21 \%, \mathrm{n}=6)$ and the mean REM $4.60 \pm 0.44 \%(2.98-6.11 \%, \mathrm{n}=6)$.

\section{Incubation and hatchling characteristics}

Among the 13 eggs inside six nests, 10 were developed $(76.9 \%, 33.3 \%-100 \%$ per nest) and 7 successfully hatched $(70 \%, 0-100 \%$ per nest). The incubation period was $85-108$ days (mean $=$ $94.7 \pm 2.5$ days; $\mathrm{n}=7$ ) and the temperature range during incubation was $17.51-29.64{ }^{\circ} \mathrm{C}$ (mean $=$ $\left.25.08 \pm 0.13^{\circ} \mathrm{C} ; \mathrm{n}=7\right)$.

The seven hatchlings had a mean weight of $9.7 \pm 0.5 \mathrm{~g}$, carapace length of $40.1 \pm 0.5 \mathrm{~mm}$, carapace width of $33.3 \pm 1.4 \mathrm{~mm}$, carapace height of $17.4 \pm 0.5 \mathrm{~mm}$, plastron length of $31.6 \pm 0.5$ $\mathrm{mm}$, and plastron width of $25.4 \pm 0.7 \mathrm{~mm}$. Hatchlings had soft, reddish-brown carapaces with curled margins that gradually flattened after several days, orange plastron and skin, and bright yellow stripes on their neck. Four bright-green eye-spots were obvious on the head, with the two spots on the same side linked together. A black dot could be seen in every eye-spot. (Fig. 4)

Two hatchings from the same clutch died two days after hatching, probably due to an ant infestation, as we found many ants on their body when the nest was opened. The remaining five hatchlings were kept in the laboratory until their yolk sac was absorbed, after which we released them to the stream in two days. 
169

170

171

172

173

174

175

176

177

178

179

180

181

182

183

184

185

186

187

188

189

190

191

192

193

194

195

\section{DISCUSSION}

The process of selecting a nesting site is important to females because they are more vulnerable to terrestrial predators at this time (Spencer, 2002). Therefore, many turtle species spend less than three hours out of water during the nesting process (Doody et al., 2009; Booth, 2010). However, we found S. bealei would spend 4-10 hours out of water when nesting. Perhaps the presence of dense forest and shrubs offers protection from predators. Additionally, the small body size and cryptic coloration (dark-brown carapace) of $S$. bealei may contribute to their safety. Turtle body size has been shown to influence reproductive potential in female turtles (Valenzuela, 2001), as the area of the pelvic girdle is correlated with female size and may constrain the size of eggs an individual can oviposit (Bowden et al., 2004). Though considered a small-sized turtle species, $S$. bealei produces larger eggs (mean length $45.5 \mathrm{~mm}$, width $23.2 \mathrm{~mm}$, weight $14.8 \mathrm{~g}$ ) than some larger freshwater species, such as T. s. elegans (egg length $35.4 \mathrm{~mm}$, width $22.1 \mathrm{~mm}$, weight $10.36 \mathrm{~g}$, Tucker \& Janzen, 1998). Continuing the comparison with T. s. elegans, S. bealei produces smaller clutches (average 2.2 eggs) of larger eggs, while T. s. elegans produces larger clutches (average 12.5 eggs) of smaller eggs. Consequently, the RCM of $S$. bealei (5.14-12.21\%) was similar to other freshwater turtle species: C. mouhotii (6.9-14.6\%, Wang et al., 2011), C. flavomarginata (2.3-9.2\%, Chen \& Lue, 1999) and T. s. scripta (3-17\%, Ernst \& Lovich 2009). Therefore, the total volume for eggs is relatively similar, but different species take different approaches to eggs - many small or few big. No correlations were found in our study between female body size and clutch size or egg size, however this may be due to small sample size. As we did not continue tracking turtles after nesting, we do not know whether females nested a second time during the breeding season. However, in captivity, females usually produced only one clutch per year (Gong et al., 2017b), implying that $S$. bealei has a low intrinsic rate of population increase.

The incubation period of $S$. bealei $\left(94.7 \pm 2.5\right.$ days at mean $\left.25.1{ }^{\circ} \mathrm{C}\right)$ was relatively long when compared to T. s. elegans (62.25 days at mean $27.4^{\circ} \mathrm{C}$, Yang, 2014) and Magdalena River Turtle (Podocnemis lewyana) (59.1 days at mean $32.8^{\circ} \mathrm{C}$, Corra-H et al., 2010). This is likely due to 
196

197

198

199

200

201

202

203

204

205

206

207

208

209

210

211

212

213

214

215

216

217

218

219

220

221

222

the nest conditions $-S$. bealei nests in cooler, shaded forests, while the other two species nest in open areas with higher nest temperatures.

Both development and hatching rate of eggs ( $76.9 \%$ and $70 \%$, respectively) in our study were higher than S. bealei in captivity (29.6\% and 62.5\%, respectively; Gong et al., 2017b). The natural habitat with lower anthropogenic disturbance may contribute the higher success of reproduction in field. Ant predation likely contributed to the death of two hatchling turtles. Ant predation is commonly reported in many other turtle species (Parris et al., 2002; Ferreira Júnior et al., 2011; Buhlmann \& Offman, 2001; Correa-H et al., 2010; Yang, 2014; Erickson \& Baccaro, 2016). In some cases, invertebrates including ants, flies, and beetles could infest more than 50\% nests (Baran et al., 2001). No evidence of vertebrate nest-predators was found in our study, probably because of the nest protection we constructed.

Successful conservation management of the endangered $S$. bealei will likely involve a combination of in-situ and ex-situ approaches. We believe the information on the reproductive ecology from our study (habitat use, nesting, breeding behavior) will help guide habitat protection and captive breeding of this rare turtle species endemic to China.

\section{ACKNOWLEDGEMENTS}

We would like to thank Wensi Wu, Jianqing Ye, Weijiang $\mathrm{Wu}$ and Jianfei Ye for the logistical support and Chenwu Shen for his great contribution in filed work.

\section{REFERENCES}

Baran İ, Özdemir A, Ilgaz Ç, Türkozan O. 2001. Impact of some invertebrates on eggs and hatchlings of the Loggerhead Turtle, Caretta caretta, in Turkey. Zoology in the Middle East 24(1):9-17.

Bobyn M, Brooks RJ. 1994. Interclutch and interpopulation variation in the effects of incubation conditions on sex, survival and growth of hatchling turtles (Chelydra serpentina) . Journal of Zoology 233:233-257. 
223

224

225

226

227

228

229

230

231

232

233

234

235

236

237

238

239

240

241

242

243

244

245

Booth DT. 2010. The natural history of nesting in two Australian freshwater turtles. Australian Zoologist 35(2):198-203.

Bowden RM, Harms HK, Paitz RT, Janzen FJ. 2004. Does optimal egg size vary with demographic stage because of a physiological constraint?. Functional Ecology 18:522-529.

Buhlmann KA, Offman GC. 2001. Fire ant predation of turtle nests and implications for the strategy of delayed emergence. The Journal of the Elisha Mitchell Scientific Society 117:94-100.

Chen TH, Lue KY. 1999. Population characteristics and egg production of the yellow-margined box turtle, Cuora flavomarginata, in northern Taiwan. Herpetologica 55(4):487-498.

Correa-H JC, Cano-Castano AM, Paez VP, Restrepo A. 2010. Reproductive ecology of the Magdalena river turtle (Podocnemis lewyana) in the Mompos Depression, Colombia. Chelonian Conservation and Biology 9(1):70-78.

Doody JS, Pauza M, Stewart B, Camacho C. 2009. Nesting Behavior of the Pig-Nosed Turtle, Carettochelys insculpta, in Australia. Chelonian Conservation and Biology 8(2): 185-191.

Ernst CH, lovich JE. 2009. Turtles of the United States and Canada. Baltimore: The Johns Hopkins University Press, 827.

Erickson J, Baccaro F. 2016. Nest predation of the yellow-spotted Amazon River turtle (Podocnemis unifilis, Troschel, 1848) by the fire ant (Solenopsis geminata, Fabricius, 1804) in the Brazilian Amazon. Herpetological Journal 26:183-186

Fan ZQ. 2001. Study on the plant community and their community species diversity in Huboliao Nature Reserve, Nanjing, Fujian, China. Master's Thesis. Xiamen: Xiamen University. [in Chinese]

Ferreira Júnior PD, Balestra RAM, Moreira JR, Freitas F de O, Lustosa APG, Jorge RF, Rosa AJM, Sampaio AA, Gomes AS. 2011. Nesting of Phrynops geoffroanus (Testudines: Chelidae) on sandy beaches along the Upper Xingu River, Brazil. Zoologia 28(5):571-576.

Gibbons JW. 1982. Reproductive patterns in freshwater turtles. Herpetologica 38:222-227.

Gong SP, Shi HT, Jiang AW, Fong JJ, Gaillard D, Wang JC. 2017a. Disappearance of 
250

251

252

253

254

255

256

257

258

259

260

261

262

263

264

265

266

267

268

269

270

271

272

273

274

275

276

endangered turtles within China's nature reserves. Current Biology 27:163-171.

Gong SP, Zhong XJ, Tao J, Chen Y, Deng JM, Ge Y, Wei YF. 2017b. Preliminary report on the captive breeding of Beale's eyed turtle (Sacalia bealei), an endangered species endemic to China. Chinese Journal of Zoology 52(2):359-360. [in Chinese]

Horne BD, Brauman RJ, Moore MJC, Seigel RA. 2003. Reproductive and nesting ecology of the yellowblotched map turtle, Graptemys flavimaculata: implications for conservation and management. Copeia 2003:729-738.

Hu QR. 2016. Ecological research of the Beal's eyed turtle (Sacalia bealei) at Huboliao National Nature Reserve, Fujian, China. Master's Thesis. Haikou: Hainan Normal University. [in Chinese]

Janzen FJ, Tucker JK, Paukstis GL. 2007. Experimental analysis of an early life-history stage: direct or indirect selection on body size of hatchling turtles? Functional Ecology 21:162170.

Li C. 2013. The field research of reproduction of Trachemys scripta elegans in Wanquan River, Hainan Province, China. Master's Thesis. Haikou: Hainan Normal University. [in Chinese]

Parris LB, Lamont MM, Carthy RR. 2002. Increased incidence of red imported fire ant (Hymenoptera: Formicidae) presence in loggerhead sea turtle (Testudines: Cheloniidae) nests and observations of hatchling mortality. Florida Entomologist 85:514-517.

Shi HT, O'Connell D, Parham J. 2005. An action plan for turtle conservation in China. Kolmarden, Sweden: Proceedings of the EAZA conference, 47-57.

Shi HT, Fong JJ, Parham JF, Pang JF, Wang JC, Hong ML, Zhang YP. 2008. Mitochondrial variation of the "eyed" turtles (Sacalia) based on known-locality and trade specimens. Molecular Phylogenetics and Evolution 49(3):1025-1029.

Spencer RJ. 2002. Experimentally testing nest site selection: fitness trade-offs and predation risk in turtles. Ecology 83:2136-2144.

Spencer RJ, Thompson MB. 2003. The significance of predation in site selection on turtles: an experimental consideration of macro- and microhabitat preferences. Oikos 102:592-600. 
277

278

279

280

281

282

283

284

285

286

287

288

289

290

291

292

293

294

295

296

297

298

Tucker JK, Moll D. 1997. Growth, reproduction, and survivorship in the red-eared turtle, Trachemys scripta elegans, in Illinois, with conservation implications. Chelonian Conservation and Biology 2:352-357.

Tucker Jk, Janzen FJ. 1998. Order of oviposition and egg size in the red-eared slider turtle (Trachemys scripta elegans). Canadian Journal of Zoology 76(2):377-380.

Valenzuela N. 2001. Maternal effects on life-history traits in the Amazonian giant river turtle Podocnemis expansa. Journal of Herpetology 35:368-378.

van Dijk PP, Iverson JB, Shaffer HB, Bour R, Rhodin AGJ. 2012. Turtles of the world, 2012 update: annotated checklist of taxonomy, synonymy, distribution, and conservation status. Chelonian Research monographs, 243-328.

Wang JC, Gong SP, Shi HT, Liu YX, Zhao EM. 2011. Reproduction and nesting of the endangered keeled box turtle (Cuora mouhotii) on Hainan Island, China. Chelonian Conservation and Biology 10(2):159-164.

Weisrock DW, Janzen FJ. 1999. Thermal and fitness relate consequences of nest location in painted turtles (Chrysemys picta). Functional Ecology 13:94-101.

Xiao FR, Shi HT, Sun L. 2014. Sexual dimorphism in body and shape in the Four- eyed spotted turtle Sacalia quadriocellata. Chinese Journal of Zoology 49:528-535. [in Chinese]

Yang JB. 2014. The ecological adaptability of Trachemys scripta elegans in brackish water of Nandu River, Hainan Island,China. Master's Thesis. Haikou: Hainan Normal University. [in Chinese]

Zhang MW, Zong Y, Ma JF. 1998. Fauna Sinica, Reptilia, Vol I. Beijing: Science Press, 140. [in Chinese] 
Figure 1

Natural habitat of Sacalia bealei

(A) An ideal stream habitat with many big stones; (B) A typical nesting site in the nearby forest, covered by heavy canopy. Photos credit: Liu Lin. 


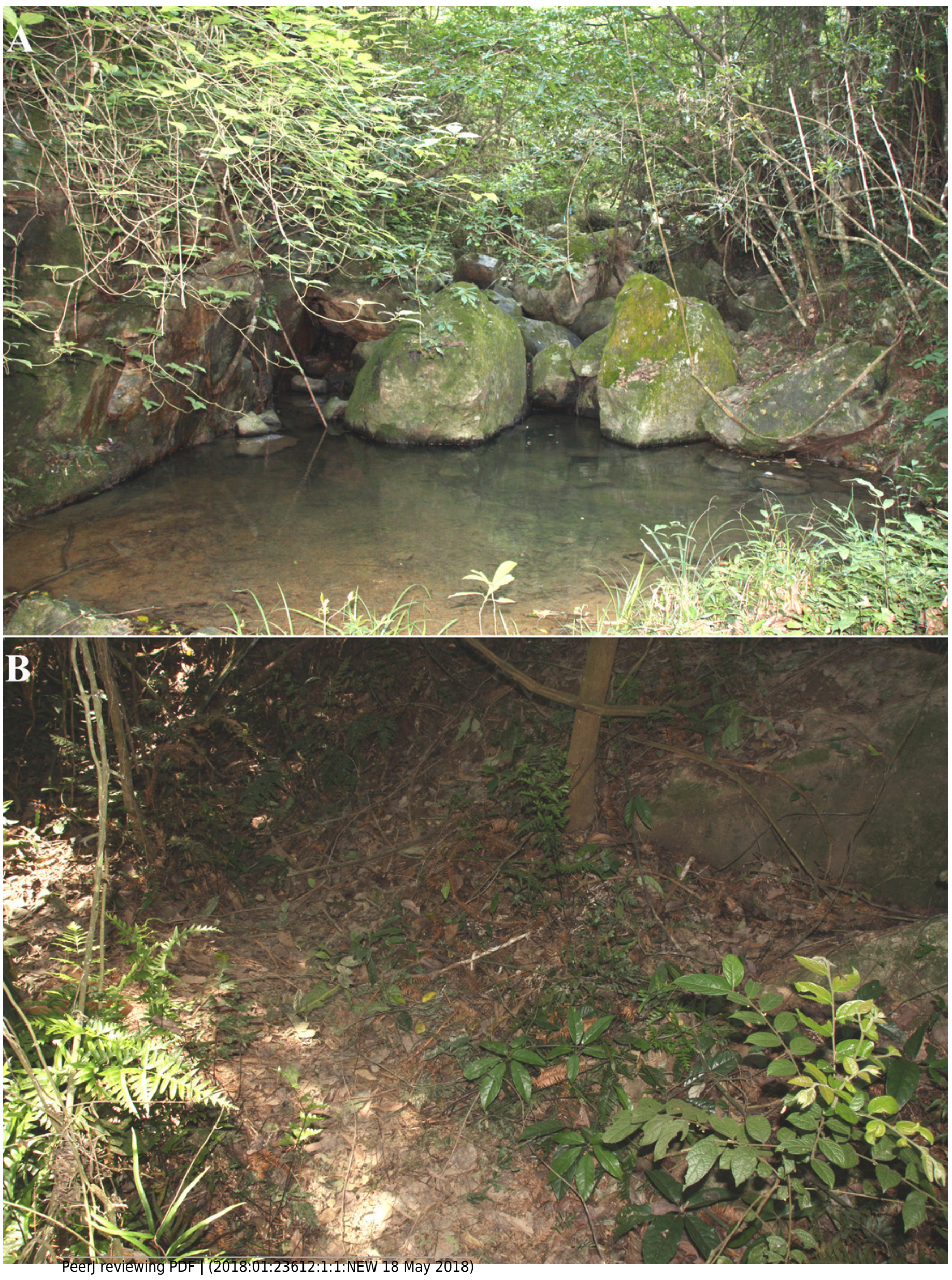


Figure 2

Tracked female turtles with a spool-and-line tracker

(A) The components of the tracker. 1, The white box with an internal line spool; 2, the fishing line; 3, the black external line spool for retrieving the line; (B) A female turtle in the wild with the tracker on her carapace.Photos credit: Qingru Hu(A), Liu Lin(B). 


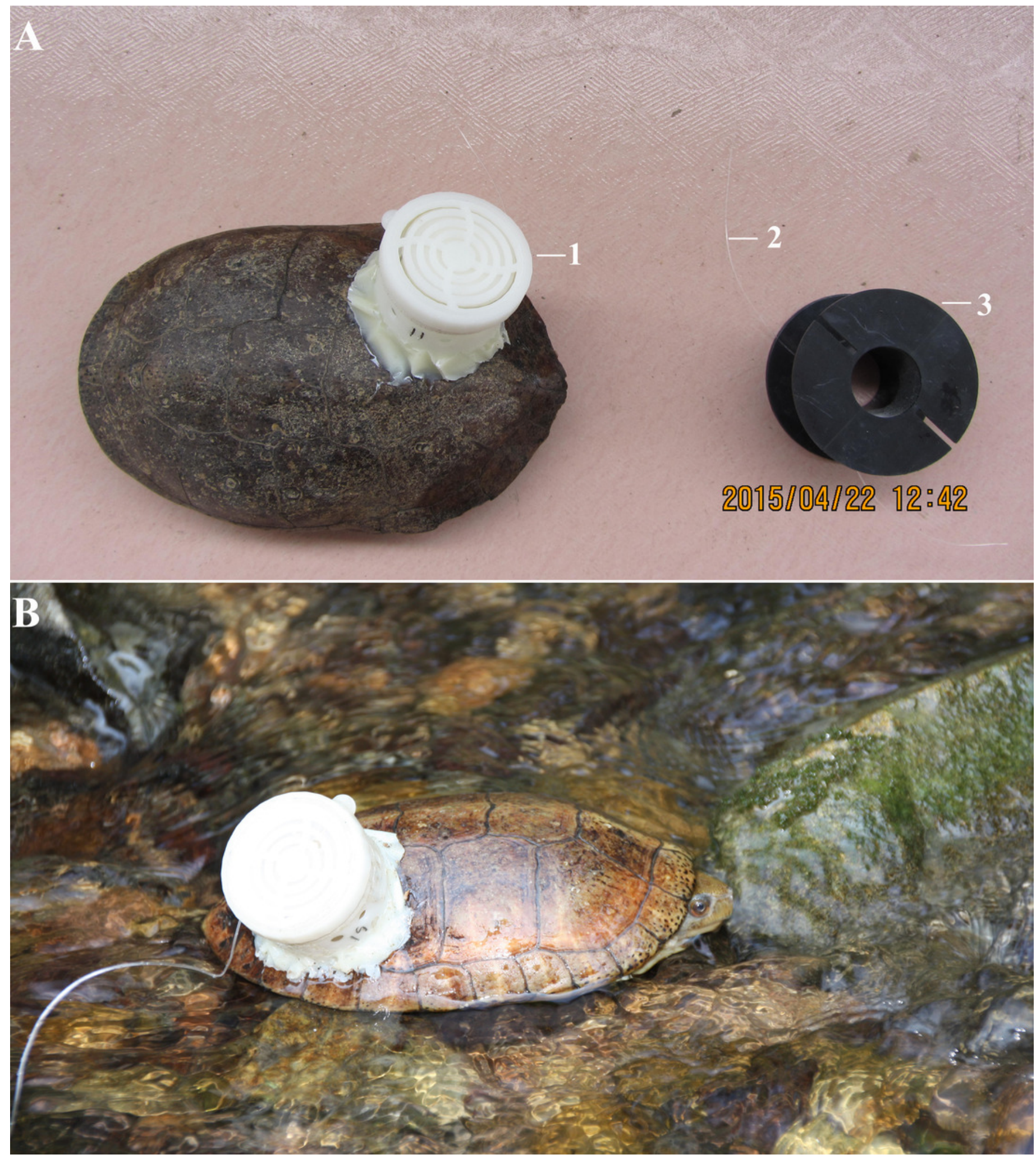


Figure 3

Well-camouflaged nest and eggs of Sacalia bealei.

(A) the nest (denoted by a circle and arrow) covered by leaves and soil; (B) two eggs inside the nest indicated by the arrow.Photos credit: Qingru Hu.
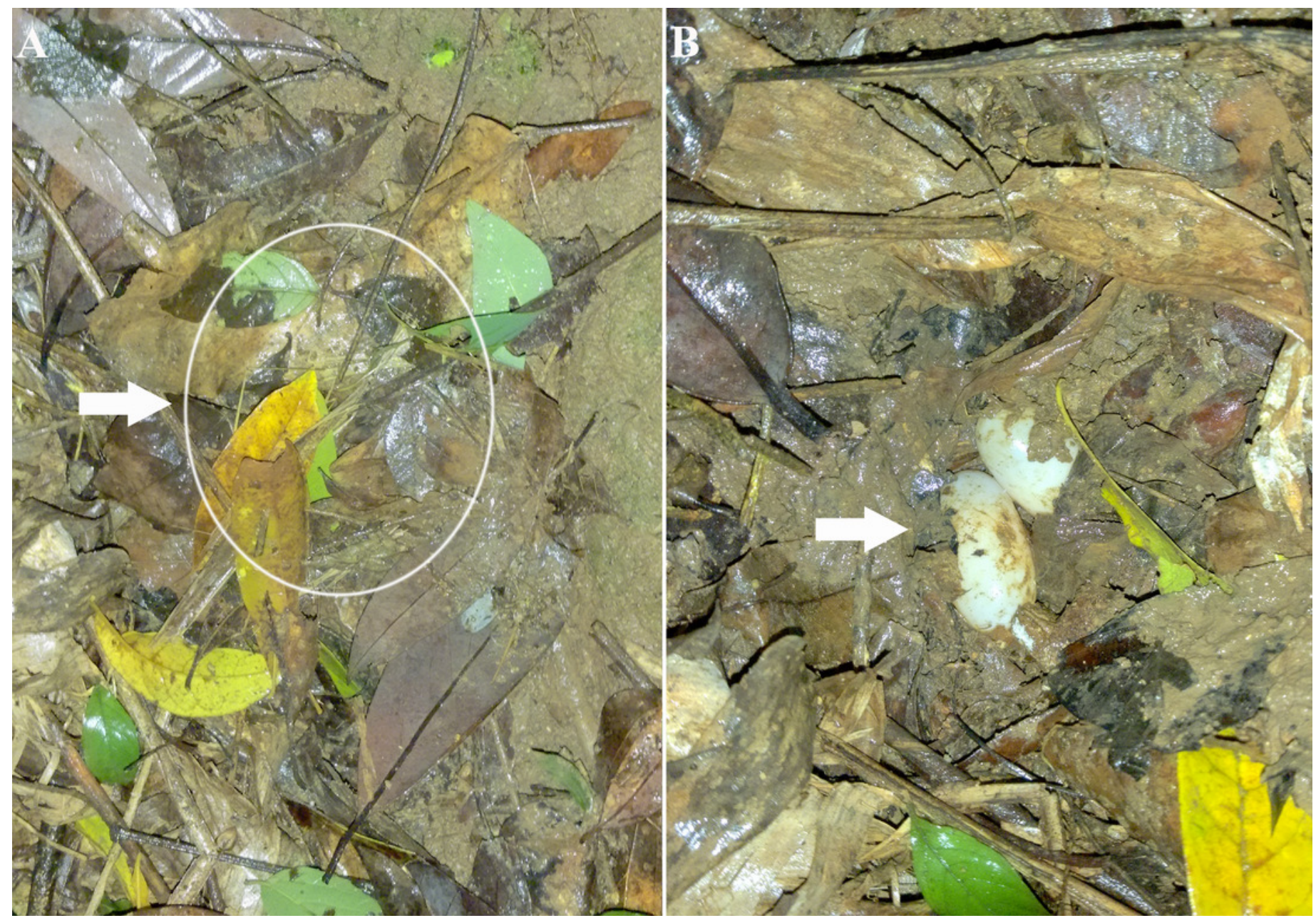
Figure 4

Hatchlings of Sacalia bealei.

(A) One hatchling emerging from the nest; (B) One-week old hatchlings.Photos credit: Qingru Hu (A), Liu Lin (B). 


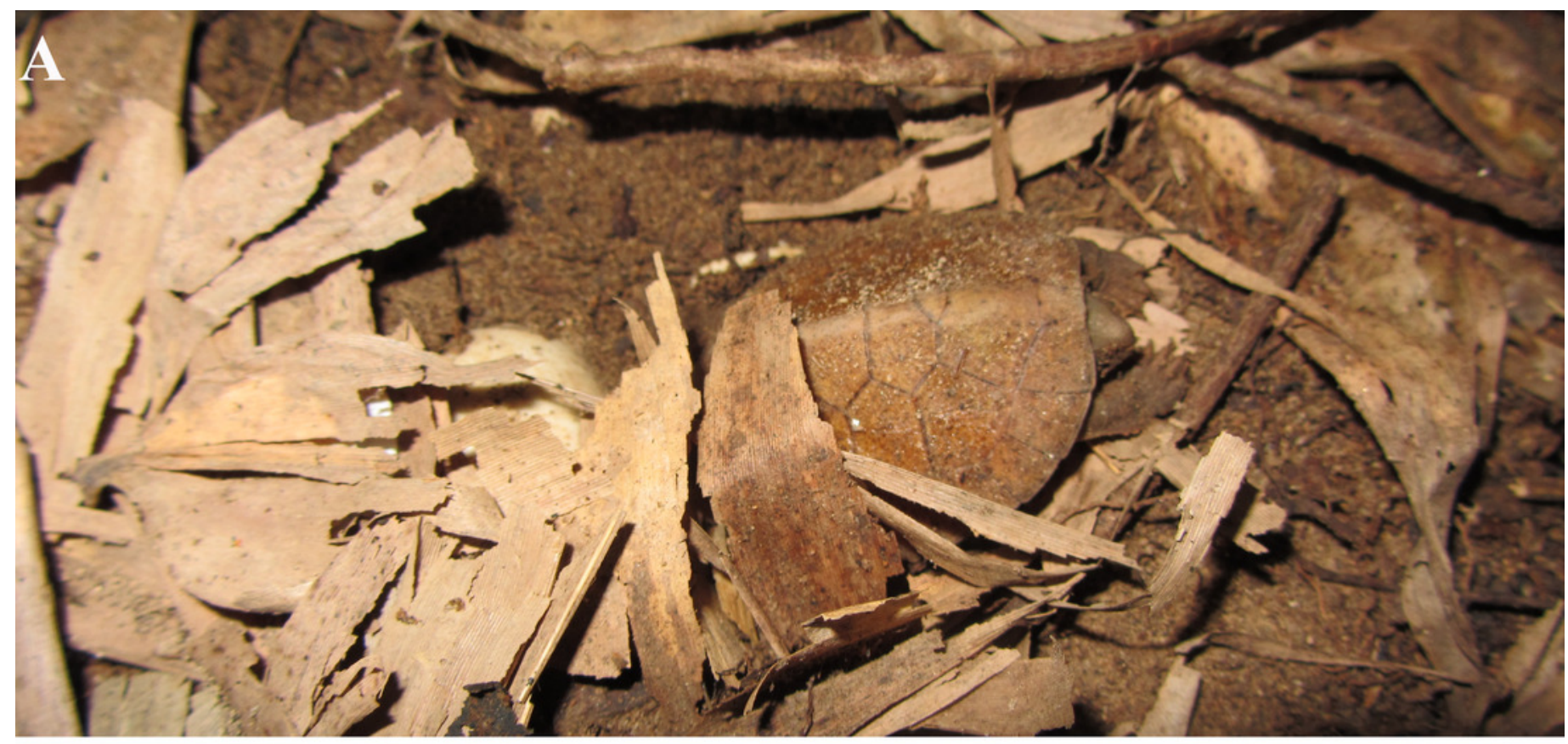

B

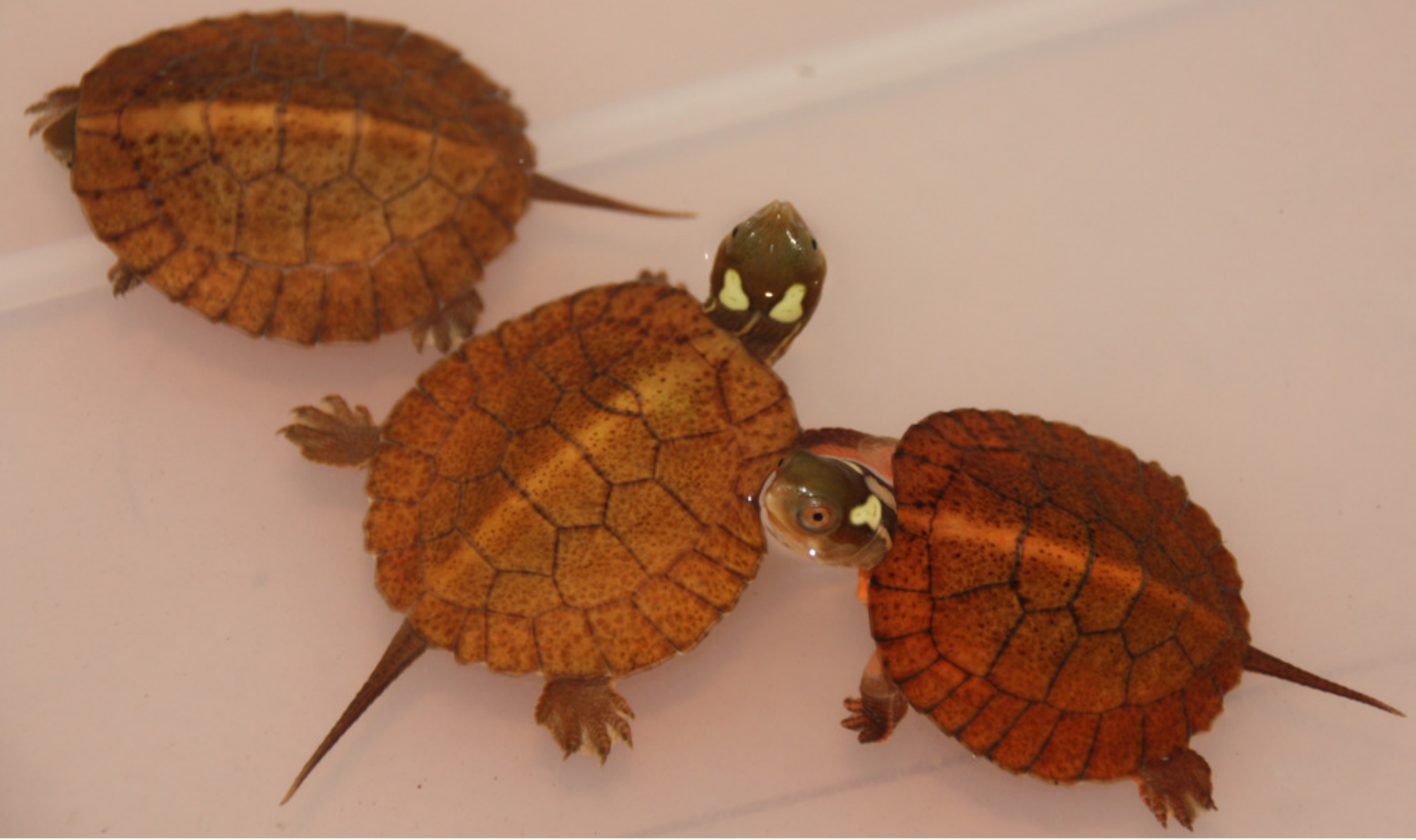

